vá xuyên vòng van, thời gian THNCT >120 phút, và đặc biệt có biến chứng hậu phẫu.Các biến chứng sau phẫu thuật với 3 biển chứng xảy ra ở 4 bệnh nhân chiếm tỉ lệ $12,5 \%$, trong đó có 1 trường hợp bị suy hô hấp do hẹp khí quản/tạo hình khí quản slideplasty và viêm phổivới tỷ lệ $18,7 \%$ và nhiễm trùng vết mổ chiếm $6,3 \%$. Trong nghiên cứu có 1 trường hợp người bệnh tử vong do bị suy tim, viêm phổi, thở máy kéo dài và tử vong trong bệnh cảnh suy đa cơ quan, chiếm tỉ lệ 3,1\%. Tỉ lệ tử vong trong nghiên cứu của chúng tôi gần tương đương so với các nghiên cứu gộp dữ liệu đa trung tâm, tổng hợp các số liệu về phẫu thuật sửa chữa ToF trên thế giới [3], [4]. Theo các tác giả, có thể giảm thấp tỉ lê tữ vong nếu bảo vê cơ tim tốt trong lúc phẫu thuật, hạn chế tối đa những tác động xấu của quá trình chạy tuần hoàn ngoài cơ thể và hoàn thiện kỹ thuật mổ và hồi sức sau mổ.

\section{KẾT LUÂN}

Tứ chứng Fallot là bệnh lý tim bẩm sinh nặng với các triệu chứng bao gồm khó thở và những cơn tím xảy ra đột ngột, có thể gây tử vong. Phẫu thuật sửa chữa toàn bộ tứ chứng Fallot cho trẻ dưới 12 tháng tuổi tiếp cận qua đường nhĩ phải và động mạch phổi với chiến lược bảo tồn van động mạch phổi với tỉ lệ tử vong thấp và ít biến chứng trong giai đoạn hồi sức và theo dõi ngắn hạn sau mổ đã khẳng định tính an toàn, hiệu quả của phẫu thuật.

\section{TÀI LIÊU THAM KHẢO}

1.Bacha E.A, Scheule A.M, Zurakowski D, Erickson L.S, Hung J, Lang P et al (2001). Long-term results after early primary repair of tetralogy of Fallot. J Thorac Cardiovasc Surg, 122; 154-161.

2.Blalock A, Taussig HB (1945). The surgical treatment of malformation of theheart in which thereis pulmonary stenosis or pulmonary atresia.JAMA; 128:189.

3. Bobae Jeon MD, Dong-Hee Kim MD et al (2020). Surgical treatment of tetralogy of Fallot in symptomatic neonates and young infants. The Journal of Thoracic and Cardiovascular Surgery, Volume 159, Issue 4, April, Pages 1477-1478

4. Loomba R. S., Buelow M. W., Woods R. K. (2017). Complete Repair of Tetralogy of Fallot in the Neonatal Versus Non-neonatal Period: A Metaanalysis. Pediatr Cardiol,38, (5), pp. 893-901

5. Kirklin JW, DuShane JW, Patrick RI, et al (1955): Intracardiac surgery withthe aid of a mechanical pump-oxygenator system (Gibbon type): reportof eight cases. Mayo Clin Proc; 30:201.

6. Seliem MA, Wu YT, Glenwright K. (1995). Relation between age at surgeryand regression of right ventricular hypertrophy in tetralogy of Fallot. Pediatr Cardiol; 16(2):53-55. Vol. 232

7. Knott-Craig CJ, Elkins RC, Lane MM, et al (1998). A 26-year experiencewith surgical management of tetralogy of Fallot: risk analysis formortality or late reintervention. Ann Thorac Surg; 66:506-511

8. Van Der Ven J. P. G., van den Bosch E., Bogers Ajcc, Helbing W. A. (2019). Current outcomes and treatment of tetralogy of Fallot. F1000Res,doi: 10.12688/ f1000research. 17174.1. eCollection 2019

\title{
TÍNH ĐA HÌNH TRÌNH TỰ GEN MÃ HÓA ND5 VÀ ND6 Ở' NGƯờI DÂN TộC GIARAI VÀ ÊĐÊ SỐNG Ở TÂY NGUYÊN
}

\author{
Nguyễn Minh Tùng*, Nguyễn Văn Ba**, Nguyễn Đăng Tôn***
}

\section{TÓM TẮT}

Mục tiêu: Xác định tính đa hình trình tự gen mã hóa ND5 và ND6 ở người dân tộc GiaRai và Ede sống ở Tây Nguyên. Đối tượng và phương pháp nghiên cứu: 54 mâ̂u máu ngoại vi của người bình thường khỏe manh, thuộc các dân tộc Giarai và Ede được tách chiết DNA, khuếch đại gen ND5, ND6 bằng phương pháp PCR, tinh sạch DNA, giải trình tự tự động. Sau

\section{*Hoc viện Quân Y \\ **Bênh viện Quân Y 103 \\ ***Viện nghiên cúu hệ gen}

Chịu trách nhiệm chính: Nguyễn Minh Tùng

Email: bsqytung@gmail.com

Ngày nhận bài: 5/5/2021

Ngày phản biên khoa học: 26/5/2021

Ngày duyệt bài: 18/6/2021 đó, trình tự gen ND5 và ND6 được phân tích và so sánh với trình tự chuẩn bằng phần mềm chuyên dụng, so sánh tính đa hình ND5, ND6 với tính đa hình được công bố trên MITOMAP. Kết quả: Đã xác định được trình tự gen mã hóa ND5, ND6 và xác định được tính đa hình trình tự gen mã hóa ND5 và ND6 ở người dân tộc GiaRai và Ede sống ở Tây Nguyên. Kết luận: Nighiên cứu đã cung cấp số liệu về tính đa hình trình tự gen mã hóa ND5 và ND6 ở người dân tộc GiaRai và Édesống ở Tây Nguyên.

Tư khóa: Tính đa hình, ND5, ND6, Gia Rai, Ede, Tây Nguyên.
SUMMARY
MITOCHONDRIAL NADH DEHYDROGENASE SUBUNIT 5 AND SUBUNIT 6 GENE POLYMORPHISMS IN GIARAI AND EDEETHNIC PEOPLE LIVING IN THE CENTRAL HIGHLANDS 
Objective:To determined the mitochondrial NADH dehydrogenase subunit 5 and $\mathrm{NADH}$ dehydrogenase subunit 6 gene polymorphisms in GiaRai and Ede ethnic people living in central highlands. Subjects and methods: 54 peripheral blood samples of healthy people from Giarai and Ede ethnic groups were extracted DNA, amplified ND5, ND6 genes by PCR, purified DNA, and sequenced automatically. Then, ND5 and ND6 gene sequences were analyzed and compared with standard sequences using specialized software, comparing ND5, ND6 polymorphisms with polymorphisms published on MITOMAP. Results: ND5, ND6 sequences and the mitochondrial NADH dehydrogenase subunit 5 and NADH dehydrogenase subunit 6 gene polymorphisms in GiaRai and Ede ethnic people living in central highlands were identified. Conclusions: This study provided data on ND5 and ND6 gene sequence and polymorphisms in GiaRai and Ede ethnic groups living in the Central Highlands.

Keywords: Polymorphisms, ND5, ND6, Gia Rai, Ede, Central Highlands.

\section{I. ĐĂT VẤN ĐỀ}

Hệ gen người gồm có hai phần: hệ gen nhân (hệ gen nhiểm sắc thể) và hệ gen tế bào chất (hệ gen ty thể). Hệ gen nhân có kích thước khoảng 3,2 tỉ bp, trong khi đó, hệ gen ty thể đã được biết đến từ năm 1981 với kích thước 16569 bp, tức là nhỏ hơn hệ gen nhân rất nhiều. Gen ND5 ty thể (mitochondrial NADH dehydrogenase subunit 5) là một trong số 37 gen chức năng mã hoá cho 13 polypeptide của chuỗi hô hấp tế bào, có chiều dài $1812 \mathrm{bp}$, nằm giữa nucleotide 12337 và 14148 [1]. Đây là gen có trình tự mã hoá liên tục, được mã hoá bởi chuỗi nặng giàu guanine của DNA ty thể [1]. Sản phẩm của gen ND5 có khối lượng phân tử khoảng 66.6 kDa, nằm ở phần kị nước của phức hệ enzyme NADH - ubiquinone oxydoreductase (phức hê I) (EC 1.6.5.3). Protein này là một trong 7 tiểu phần được mã hoá bởi DNA ty thể trong số 42 tiểu phần của phức hệ I của chuỗi hô hấp [2]. Các nghiên cứu trên thế giới về gen ND5 tập trung chủ yếu vào nghiên cứu các quan hệ di truyền theo mẫu hệ, phân loại các nhóm đơn bội (haplogroups) và các dòng phả hệ hoă̆c nghiên cứu về các bệnh di truyền liên quan đến ty thể như bệnh liệt thần kinh thị giác di truyền Leber (Leber hereditary optic neuropathy, LHON), Leigh, bệnh viêm não tủy nhiễm lactic acid với các tình tiết giống đột quy. (Mitochondrial Encephalomyopathy, Lactic Acidosis, and Strokelike episodes - MELAS)...

Gen ND6 ty thể (mitochondrial NADH dehydrogenase subunit 6) nằm trên chuỗi nhe của phân tử DNA ty thể từ vị trí nucleotide 14149 đến 14673 [1], gồm 525 cặp base với trình tự mã hoá liên tục, không có các đoạn intron. Gen ND6 là gen chức năng, tuy có kích thước không lớn, nhưng lại chứa tương đối nhiều điểm đột biến gây ra các bệnh ty thể, đặc biệt là LHON, Leigh và MELAS.

\section{II. ĐỐI TƯỢNG VÀ PHƯƠNG PHÁP NGHIÊN CỨU}

2.1. Đối tượng nghiên cứu. Đối tượng nghiên cứu là các mẫu máu ngoại vi của người bình thường, khỏe mạnh, thuộc các dân tộc Giarai và Êde.

\subsection{Phương pháp nghiên cứu}

- Tách chiết DNA tổng số từ máu:

DNA tổng số được tách chiết từ các mẫu máu toàn phần lưu giữ ở nhiệt độ $-80^{\circ} \mathrm{C}$ theo phươngpháp của Sambrook và Russell (2001).

- Khuếch đại và xác định trình tự gen ND5 và ND6 DNA ty thể:

+ Mồi: Gen ND5 và gen ND6 được khuếch đại bằng kỹ thuật $P C R$, sử dụng cặp mồi đặc hiệu $N D 5 F / R$ và ND6F/R, tương ứng.

Bảng 2.1. Trình tự mồi khuếch đại gen ND5 và ND6

\begin{tabular}{|c|c|}
\hline Tên mồi & Trình tự mồi \\
\hline ND5F & $\begin{array}{c}5^{\prime} \text { - AGG ACT CAA CAT ACT AGT CAC } \\
\text { AGC - } 3^{\prime}\end{array}$ \\
\hline ND5R & $5^{\prime}$-GAG GTC GAT GAA TGA GTG GTT-3' \\
\hline ND5F & $5^{\prime}$ - GCACAATCCCCTATCTAGGC-3' \\
\hline ND5R & $5^{\prime}$-GAGGTCGATGAATGAGTGGTT- $3^{\prime}$ \\
\hline
\end{tabular}

+ Hỗn hợp phản ứng: bao gồm 0,625 đơn vị Taq DNA polymerase, $1 \times$ đệm PCR, $250 \mu \mathrm{M}$ dNTP mỗi loại, 10 pM mỗi loại mồi và 500 ng DNA tổng số.

+ Chu trình nhiệt: Kỹ thuật PCR được tiến hành trên máy luẩn nhiêt (Eppendorf Master Cycler) với chu trình nhiệt như sau: $96^{\circ} \mathrm{C}, 3$ phút; 35 chu kỳ $\left(96^{\circ} \mathrm{C}, 20\right.$ giây; $58^{\circ} \mathrm{C}, 1$ phút; $72^{\circ} \mathrm{C}$, 1 phút 20 giây); $72^{\circ} \mathrm{C}, 10$ phút, sau đó giữ ở $4^{\circ} \mathrm{C}$. Sản phẩm $\mathrm{PCR}$ được đó tinh sạch bằng Kit SV Wizard của hãng Promega theo phương pháp của nhà sản xuất.

- Giải trình tự gen ND5 và ND6: sử dụng hệ thống máy giải trình tự tự động ABI PRISM 3500 Genetic Analyzer sử dụng bộ kit BigDye Terminator v3.1 (Applied Biosystems).

- Xử lý và phân tích trình tự: Trình tự gen ND5 và ND6 của DNA ty thể của 54 cá thể người Việt Nam đã được phân tích, so sánh với trình tự chuẩn Cambridge (rCRS) đã được công bố trên Ngân hàng dữ liệu về DNA ty thể [3] bằng các phần mềm sinh học chuyên dụng SeqScape v2.6, ClustalX v2.0... Đồng thời cũng so sánh các đặc điểm đa hình của các mẫu nghiên cứu với các đặc điểm đa hình đã được công bố trên 
MITOMAP (Mitomap: A Human Mitochondrial Genome Database. http://www. mitomap.org).

\section{KẾT QUẢ NGHIÊN CứU}

\subsection{Kết quả quá trình xác định trình tự} gen ND5 và ND6

DNA tổng số đã được tách chiết, tinh sạch và kiểm tra nồng độ bằng quang phổ, dùng làm khuôn để nhân đoạn gen ND5. Kết quả điện di sản phẩm PCR thu được ở hình 3.1.

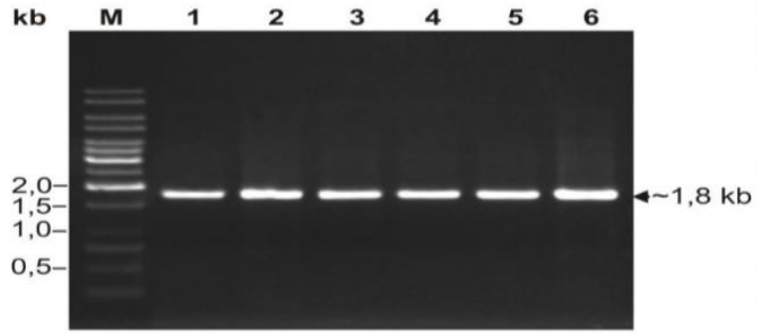

Hình 3.1. Kết quả điện di sản phẩm $P C R$ nhân đoạn gen ND5 trên gel agarose 0,8\%

M: Thang DNA chuẩn. Các đường chạy được đánh số tương ứng với môt số mẫu thuộc dẩn tộc Ede và Giarai.

Kết quả cho thấy đều thu được sản phẩm $\mathrm{PCR}$ đặc hiệu, rõ nét ở các mẫu nghiên cứu. Kích thước của các sản phẩm $\mathrm{PCR}$ này đều phù hợp với các tính toán lý thuyết ở trên. Kết quả còn cho thấy cặp mồi sử dụng có tính đặc hiệu cao và chu trình nhiệt để nhân đoạn gen ND5 đã được tối ưu hóa. Các sản phẩm PCR này đủ tiêu chuẩn để dùng cho các bước thí nghiệm tiếp theo.

Tương tự, đối với gen ND6, kết quả điện di ở hình 3.2. cho thấy ở tất cả các đường chạy đều xuất hiện băng DNA có kích thước khoảng 900bp theo tính toán lý thuyết. Các băng đều sáng đậm, rõ nét, không có băng phụ chứng tỏ chu trình lựa chọn và nồng độ thành phần tham gia phản ứng là thích hợp.

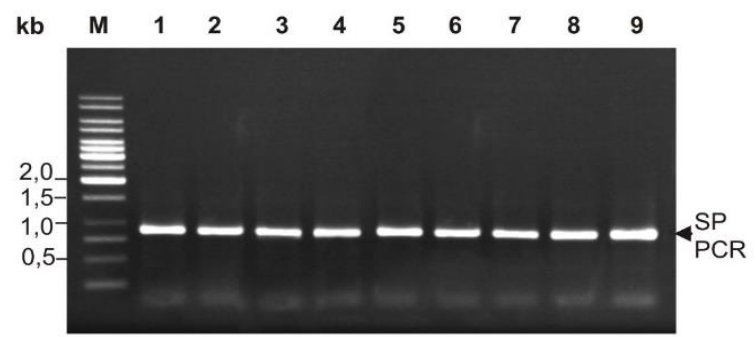

Hình 3.2. Kêt quả điện di sản phẩm $P C R$ nhân đoạn gen ND6 trên gel agarose 0,8\%

M: Thang DNA chuẩn. Các đường chạy được đánh số tương ứng với một số mẫu thuộc dẩn tộc Ede và Giarai.

Chúng tôi tiến hành phân tích và lắp ghép các trình tự nucleotide thu được và đã có trình tự hoàn chỉnh của gen ND5 và ND6.Trình tự của gen ND5 có kích thước 1812 bp, được xác định từ vị trí 12337 đến 14148. Gen ND6 là gen chức năng, sản phẩm của nó là chuỗi polypeptide bao gồm 174 amino acid. Amino acid đầu tiên trong chuỗi được mã hoá bởi mã bộ ba bắt đầu từ vị trí nucleotide 14673 đến 14671. Với trình tự gen ND5 và ND6 đã xác định được (bảng 3.1, bảng 3.2), chúng tôi xác định tính đa hình của trình tự gen ND5 và ND6 so với trình tự chuẩn Cambridge (rCRS), thu được các kết quả liệt kê ở mục 3.2. dưới đây.

3.2.Tính đa hình trình tứ gen ND5 và ND6. Kết quả tính đa hình trình tự gen ND5 và ND6 so với trình tự chuẩn Cambridge chúng tôi thu được bảng sau:

Bảng 3.2. Các điểm thay đổi nucleotide trên gen ND5 và ND6 ở các mẫu nghiên cứu

\begin{tabular}{|c|c|c|c|c|c|c|c|c|c|c|c|c|c|c|c|c|c|c|c|c|c|c|c|c|c|c|c|c|}
\hline & $\begin{array}{c}12 \\
36 \\
7 \\
\end{array}$ & $\begin{array}{c}12 \\
37 \\
4\end{array}$ & $\begin{array}{c}12 \\
41 \\
8\end{array}$ & $\begin{array}{c}12 \\
41 \\
9\end{array}$ & $\begin{array}{c}12 \\
62 \\
5\end{array}$ & $\begin{array}{c}12 \\
66 \\
4\end{array}$ & $\begin{array}{c}12 \\
78 \\
4\end{array}$ & $\begin{array}{c}12 \\
82 \\
4\end{array}$ & $\begin{array}{c}13 \\
11 \\
8\end{array}$ & \begin{tabular}{|c|}
13 \\
15 \\
8 \\
\end{tabular} & $\begin{array}{c}13 \\
21 \\
9\end{array}$ & $\begin{array}{c}13 \\
27 \\
6\end{array}$ & $\begin{array}{c}13 \\
28 \\
9\end{array}$ & $\begin{array}{c}13 \\
45 \\
0\end{array}$ & $\begin{array}{c}13 \\
51 \\
9\end{array}$ & $\begin{array}{c}13 \\
66 \\
3\end{array}$ & $\begin{array}{c}13 \\
77 \\
2\end{array}$ & \begin{tabular}{|c|}
13 \\
81 \\
9
\end{tabular} & \begin{tabular}{|c|}
13 \\
82 \\
5
\end{tabular} & $\begin{array}{c}13 \\
94 \\
1\end{array}$ & $\begin{array}{l}14 \\
04 \\
7\end{array}$ & $\begin{array}{c}14 \\
12 \\
3\end{array}$ & $\begin{array}{c}14 \\
17 \\
9\end{array}$ & \begin{tabular}{|l|}
14 \\
20 \\
8 \\
\end{tabular} & \begin{tabular}{|l}
14 \\
23 \\
2
\end{tabular} & \begin{tabular}{|c}
14 \\
28 \\
3
\end{tabular} & $\begin{array}{c}14 \\
31 \\
7\end{array}$ & $\begin{array}{c}14 \\
55 \\
9\end{array}$ \\
\hline & \multicolumn{22}{|c|}{ ND5 } & \multicolumn{6}{|c|}{ ND6 } \\
\hline $\begin{array}{c}\text { RCR } \\
\text { S }\end{array}$ & $\mathbf{T}$ & $\mathbf{A}$ & C & $\mathbf{G}$ & $\mathbf{A}$ & $\mathbf{G}$ & G & $\mathbf{T}$ & G & G & C & $\mathbf{A}$ & G & $\mathbf{T}$ & $\mathbf{T}$ & $\mathbf{T}$ & G & C & $\mathbf{T}$ & $\mathbf{G}$ & $\mathbf{T}$ & $\mathbf{T}$ & $\mathbf{T}$ & $\mathbf{A}$ & A & C & $\mathbf{T}$ & G \\
\hline $\begin{array}{r}\text { Ed01 } \\
\text { M68 }\end{array}$ & . & . & . & . & . & . & . & . & $A$ & . & . & . & $A$ & . & C & C & . & $\mathrm{T}$ & . & . & . & . & . & . & G & . & . & - \\
\hline $\begin{array}{l}\text { Ed02 } \\
\text { M68 }\end{array}$ & $\cdot$ & . & . & . & . & . & . & . & A & . & . & . & A & . & C & C & . & $\mathrm{T}$ & . & . & . & . & C & . & G & . & . & . \\
\hline $\begin{array}{r}\text { Ed03 } \\
\text { M68 }\end{array}$ & - & . & . & . & . & . & . & . & A & . & . & . & A & . & C & $\mathrm{C}$ & . & $\mathrm{T}$ & . & . & . & . & C & . & G & . & . & . \\
\hline $\begin{array}{r}\text { Ed04 } \\
\text { M21 }\end{array}$ & - & . & . & . & $\mathrm{G}$ & . & . & . & A & . & $\mathrm{T}$ & . & A & . & C & C & . & . & . & . & . & . & . & . & . & . & . & . \\
\hline $\begin{array}{l}\text { Ed05 } \\
\text { M73 }\end{array}$ & - & . & . & . & . & . & . & . & A & . & . & . & A & . & C & $\mathrm{C}$ & . & . & . & . & C & . & . & . & . & . & . & . \\
\hline $\begin{array}{l}\text { Ed06 } \\
\text { F1f }\end{array}$ & . & . & . & $A$ & . & . & A & . & A & . & . & . & $A$ & . & C & $\mathrm{C}$ & A & . & . & . & . & . & . & . & . & . & . & 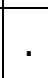 \\
\hline
\end{tabular}




\begin{tabular}{|c|c|c|c|c|c|c|c|c|c|c|c|c|c|c|c|c|c|c|c|c|c|c|c|c|c|c|c|c|}
\hline \begin{tabular}{|} 
Ed07 \\
M24
\end{tabular} & . & . & . & . & . & $A$ & . & . & A & . & . & . & $A$ & . & $C$ & C & . & . & $C$ & . & . & . & & . & . & . & . & \\
\hline $\begin{array}{r}\text { Ed08 } \\
\text { M71 }\end{array}$ & . & . & . & . & . & . & . & . & A & . & . & . & $A$ & . & $C$ & C & & . & . & . & . & . & & . & . & . & $\cdot$ & \\
\hline \begin{tabular}{|} 
Ed09 \\
M71
\end{tabular} & . & . & . & . & . & . & . & & A & . & . & . & $A$ & & $C$ & C & & & . & & . & & & . & . & . & & \\
\hline \begin{tabular}{|} 
Ed10 \\
M71
\end{tabular} & . & . & . & . & . & . & . & . & A & . & . & . & $A$ & & $C$ & C & & . & . & . & . & & & & . & $\mathrm{T}$ & & \\
\hline $\mid \begin{array}{r}\text { Ed11 } \\
\text { M71 }\end{array}$ & . & . & . & . & . & . & . & . & A & . & . & . & $A$ & . & C & C & . & . & . & . & . & . & & . & . & $\mathrm{T}$ & . & \\
\hline $\mid \begin{array}{r}\text { Ed12 } \\
\text { M71 }\end{array}$ & . & . & . & . & . & . & . & & A & . & . & . & $A$ & . & $C$ & C & & . & . & . & . & & & . & . & . & & \\
\hline \begin{tabular}{|} 
Ed13 \\
M71
\end{tabular} & . & . & . & . & . & . & . & . & A & . & . & . & A & . & $C$ & C & & . & . & . & . & . & & . & . & . & $\cdot$ & \\
\hline \begin{tabular}{|} 
Ed14 \\
M71
\end{tabular} & . & . & . & . & . & . & . & & A & . & . & $\cdot$ & A & . & $C$ & C & & . & . & . & . & . & & . & . & . & & \\
\hline $\begin{array}{r}\text { Ed15 } \\
\text { M71 }\end{array}$ & . & . & . & . & . & . & . & & A & . & . & . & A & . & $C$ & C & & & . & . & . & & & & . & . & & \\
\hline 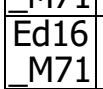 & . & . & . & . & . & . & . & & A & . & . & . & A & . & $C$ & C & & . & . & . & . & . & & . & . & . & & \\
\hline $\begin{array}{r}\text { Ed17 } \\
\text { M71 }\end{array}$ & . & . & . & . & . & . & . & . & A & $\cdot$ & . & $\cdot$ & A & . & $C$ & C &. & . & . & . & . & . & ${ }^{\prime}$ & . & . & . & . & . \\
\hline \begin{tabular}{|r|} 
Ed18 \\
M74
\end{tabular} & . & . & . & . & . & A & . & & A & . & . & . & A & . & $C$ & C & & . & . & . & . & & & . & . & . & & \\
\hline $\begin{array}{r}\text { Ed19 } \\
\text { B5A }\end{array}$ & . & . & . & . & . & . & . & . & $A$ & $A$ & . & . & A & . & $C$ & C & 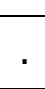 & . & . & . & . & . & ${ }^{\circ}$ & . & . & . & . & . \\
\hline \begin{tabular}{|}
$\mathrm{Ed} 20$ \\
$\mathrm{~B} 5 \mathrm{~A}$
\end{tabular} & . & . & . & . & . & . & . & . & $A$ & A & . & . & A & . & $C$ & C & . & . & . & . & $\cdot$ & . & . & . & . & . & . & . \\
\hline $\mid \begin{array}{r}\mathrm{Ed} 21 \\
\text { B5A }\end{array}$ & . & . & . & . & . & . & . & . & $A$ & $A$ & . & . & A & . & $C$ & C & . & . & . & . & . & . & . & . & . & . & . & . \\
\hline $\begin{array}{r}\mathrm{Ed} 22 \\
\mathrm{~B} 5 \mathrm{~A}\end{array}$ & . & . & . & . & . & . & . & . & $A$ & $A$ & . & . & A & . & $C$ & C & . & . & . & . & . & . & . & . & . & . & . & . \\
\hline $\begin{array}{r}\mathrm{Ed23} \\
\mathrm{B} 5 \mathrm{~A}\end{array}$ & . & . & . & . & . & . & . & . & A & $\cdot$ & . & . & $A$ & . & $C$ & C & . & . & . & . & . & . & . & G & . & . & . & . \\
\hline \begin{tabular}{|}
$\mathrm{Ed24}$ \\
$\mathrm{B} 5 \mathrm{~A}$
\end{tabular} & . & . & . & $\cdot$ & . & . & . & . & A & $\cdot$ & . & . & $A$ & . & $C$ & C & . & . & . & . & . & . & . & . & . & . & . & . \\
\hline $\begin{array}{r}\mathrm{E} \\
\mathrm{Ed} 25 \\
\mathrm{~B} 5 \mathrm{~A}\end{array}$ & . & $\cdot$ & . & . & . & . & . & . & $A$ & $\cdot$ & . & . & $A$ & . & $C$ & C & . & . & . & . & $\cdot$ & . & . & . & . & . & . & . \\
\hline $\mid \begin{array}{r}\text { Ed26 } \\
\text { N21 }\end{array}$ & . & . & . & . & . & . & . & . & A & $\cdot$ & . & . & $A$ & C & $C$ & C & . & . & . & . & . & . & . & . & . & . & . & A \\
\hline \begin{tabular}{|r|} 
GR01 \\
M20
\end{tabular} & $C$ & . & . & . & . & . & . & . & A & $\cdot$ & . & . & $A$ & . & $C$ & C & . & . & . & . & $\cdot$ & C & . & . & . & . & . & . \\
\hline $\mid$\begin{tabular}{r|} 
GR02 \\
M20
\end{tabular} & C & . & . & . & . & . & . & . & A & . & . & . & A & . & $C$ & C & . & . & . & . & $\cdot$ & C & . & . & . & . & . & . \\
\hline \begin{tabular}{|r|} 
GR03 \\
M20
\end{tabular} & C & . & . & . & . & . & . & . & A & . & . & . & $A$ & . & $C$ & C & . & . & . & . & $\cdot$ & C & . & . & . & . & . & . \\
\hline \begin{tabular}{|r|} 
GR04 \\
M20
\end{tabular} & $C$ & . & . & . & . & . & . & . & $A$ & . & . & . & A & . & $C$ & C & . & . & . & . & $\cdot$ & C & . & . & . & . & . & . \\
\hline $\begin{array}{r}\text { GR05 } \\
\text { M21 }\end{array}$ & . & . & . & . & G & . & . & . & $A$ & . & . & . & A & . & $C$ & C & . & . & . & . & $\cdot$ & . & . & . & . & . & $\cdot$ & . \\
\hline $\mid \begin{array}{r}\text { GR06 } \\
\text { M21 }\end{array}$ & . & . & . & . & G & . & . & . & $A$ & . & . & . & A & . & $C$ & C & . & . & . & . & . & . & . & $\cdot$ & . & . & . & . \\
\hline $\begin{array}{r}\text { GR07 } \\
\text { M21 }\end{array}$ & . & $\cdot$ & . & . & G & . & . & $\cdot$ & $A$ & . & . & $\cdot$ & A & . & $C$ & C & & . & . & . & . & . & . & . & $\cdot$ & . & . & . \\
\hline $\begin{array}{l}\text { GR08 } \\
\text { M7b }\end{array}$ & . & . & $T$ & . & . & . & . & C & $A$ & . & . & $\cdot$ & A & . & $C$ & C & & . & $\cdot$ & . & $\cdot$ & . & . & $\cdot$ & . & . & $\cdot$ & . \\
\hline $\begin{array}{r}\text { GR09 } \\
\text { M7b }\end{array}$ & $\cdot$ & $\mathrm{G}$ & $\mathrm{T}$ & . & . & . & . & C & A & $\cdot$ & . & $\cdot$ & A & $\cdot$ & C & C & & $\cdot$ & $\cdot$ & . & $\cdot$ & . & . & $\cdot$ & . & $\cdot$ & $\cdot$ & . \\
\hline GR10 &. & . & & . & & & . & & $A$ & & & & A & & C & $\mathrm{C}$ & & & & & C & & & & & & & \\
\hline
\end{tabular}




\begin{tabular}{|c|c|c|c|c|c|c|c|c|c|c|c|c|c|c|c|c|c|c|c|c|c|c|c|c|c|c|c|c|}
\hline \\
\hline \multicolumn{28}{|l|}{\begin{tabular}{|l|} 
GR1/3 \\
\end{tabular}} & . \\
\hline $\begin{array}{r}\text { GR12 } \\
\text { F1A }\end{array}$ & . & . & . & A & . & . & . & . & A & . & . & . & $A$ & . & C & C & A & . & . & C & . & . & . & . & . & . & ' & . \\
\hline $\begin{array}{r}\overline{\text { GR13 }} \\
\text { F1A } \\
\end{array}$ & . & · & . & A & . & . & . & . & $A$ & . & . & . & $A$ & . & C & C & A & . & . & C & . & . & . & . & . & . & . & . \\
\hline $\begin{array}{r}\text { GR14 } \\
\text { M71 } \\
\end{array}$ & $\cdot$ & . & . & $\cdot$ & . & $\cdot$ & . & $\cdot$ & A & . & . & . & $A$ & . & C & C & . & . & . & $\cdot$ & . & . & . & . & . & . & . & . \\
\hline $\begin{array}{r}\overline{\mathrm{G}} \mathrm{R} 15 \\
\mathrm{M} 71\end{array}$ & $\cdot$ & . & . & . & . & . & . & . & A & . & . & . & A & . & C & C & . & . & . & . & . & $\cdot$ & . & . & . & . & $\cdot$ & . \\
\hline $\begin{array}{r}\overline{\mathrm{G}} \mathrm{R} 16 \\
\mathrm{M} 11\end{array}$ & . & . & . & . & . & . & . & . & A & . & . & . & $A$ & . & C & C & . & . & . & . & . & . & . & . & . & . & . & . \\
\hline $\begin{array}{r}\text { GR17 } \\
\text { M71 }\end{array}$ & . & $\cdot$ & . & . & $\cdot$ & $\cdot$ & . & . & A & . & . & . & $A$ & . & C & C & . & . & . & . & . & $\cdot$ & . & . & . & . & . & . \\
\hline $\begin{array}{r}\text { GR18 } \\
\text { M71 }\end{array}$ & . & . & . & . & $\cdot$ & . & . & . & A & . & . & . & $A$ & . & C & C & . & . & . & . & . & . & . & . & . & . & . & . \\
\hline $\begin{array}{r}\text { GR19 } \\
\text { M71 }\end{array}$ & · & $\cdot$ & . & $\cdot$ & . & $\cdot$ & . & . & A & . & . & . & A & . & C & C & . & . & . & . & . & . & . & . & . & . & . & . \\
\hline $\begin{array}{r}\text { GR20 } \\
\text { M71 }\end{array}$ & . & . & . & . & $\cdot$ & $\cdot$ & . & $\cdot$ & $A$ & . & . & . & $A$ & . & C & C & . & . & . & $\cdot$ & . & . & . & $\cdot$ & . & . & · & . \\
\hline $\begin{array}{r}\text { GR21 } \\
\text { M71 }\end{array}$ & $\cdot$ & . & . & . & $\cdot$ & . & . & $\cdot$ & A & $\cdot$ & . & . & $A$ & . & C & C & . & $\cdot$ & . & $\cdot$ & . & . & . & $\cdot$ & . & . & . & . \\
\hline \begin{tabular}{|r|} 
GR22 \\
M71
\end{tabular} & $\cdot$ & . & $\cdot$ & . & $\cdot$ & . & . & $\cdot$ & A & . & . & . & $A$ & . & C & C & . & . & . & . & . & . & . & $\cdot$ & . & . & · & . \\
\hline $\begin{array}{r}\text { GR23 } \\
\text { M71 }\end{array}$ & $\cdot$ & . & . & . & . & . & . & $\cdot$ & A & . & . & . & $A$ & . & C & C & . & . & . & . & . & . & $\cdot$ & . & . & . & . & . \\
\hline $\begin{array}{r}\text { GR24 } \\
\text { M74 }\end{array}$ & $\cdot$ & . & $\cdot$ & . & . & A & . & . & A & . & . & . & A & . & C & C & . & . & . & . & . & . & . & . & . & . & . & . \\
\hline $\begin{array}{r}\text { GR25 } \\
\text { M74 }\end{array}$ & . & . & . & . & . & A & . & . & A & . & . & . & A & . & C & $\mathrm{C}$ & . & . & . & . & . & . & . & . & . & . & . & . \\
\hline $\begin{array}{r}\text { GR26 } \\
\text { R9b }\end{array}$ & - & . & . & $\cdot$ & . & . & . & . & A & . & . & . & A & . & C & C & . & . & . & C & . & . & . & . & . & . & . & . \\
\hline $\begin{array}{r}\text { GR27 } \\
\text { N21 } \\
\end{array}$ & $\cdot$ & $\cdot$ & . & $\cdot$ & . & - & . & . & A & . & . & . & A & C & C & C & . & . & . & . & . & . & . & . & . & . & . & $A$ \\
\hline $\begin{array}{r}\text { GR28 } \\
\text { N21 }\end{array}$ & . & . & . & . & . & . & & . & $A$ & & . & . & $A$ & C & $C$ & C & . & & . & . & $\mathrm{T}$ & . & . & . & . & . & . & $A$ \\
\hline
\end{tabular}

Bảng trên cho thấy, kết quả so sánh trình tự gen ND5 các mẫu nghiên cứu và trình tự chuẩn có sự khác biệt ở 22 vị trí nucleotide, trong đó, có 4 điểm khác biệt trình tự nucleotide xuất hiện ở cả 54 mấu nghiên cứu là G13118A, G13289A, $\mathrm{T} 13519 \mathrm{C}$ và $\mathrm{T} 13663 \mathrm{C}$. Điểm đa hình A12374G, G12784A và T13825C chỉ xuất hiện ở 1 mẫu nghiên cứu tương ứng là GR09, Edi18 và Ed07. Như vậy, chúng tôi nhận thấy đoạn gen này có sự đa hình giữa 54 cá thể và nằm trong phạm vi dao động khác biệt giữa các cá thể người.

Để các định ảnh hưởng của các thay đổi về nucleotid đển sự thay đổi trật tự amino acid, chúng tôi tiến hành so sánh trình tự amino acid của 54 mẫu nghiên cứu so với trình tự chuẩn. Kết quả cho thấy trong số 22 thay đổi nucleotide thì có 8 thay đổi nucleotide dẫn đến thay đổi amino acid, trong đó có 5 thay đổi về amino acid đã được công bố là T8A, V24I, Y159H, A458T và A475T. Trình tự gen ND6 của 54 cá thể nghiên cứu được so sánh với trình tự chuẩn Cambridge
(rCRS), ba trình tự đại diện cho người châu á gồm Trung Quốc, Nhật Bản và Ấn Độ và hai trình tự đại diện cho người châu Mỹ gồm Bắc Mỹ và Nam Mỹ. Trong 54 mẫu nghiên cứu chúng tôi chỉ phát hiện được 6 điểm đa hình trên gen ND6 là T14179C, A14208G, A14232G, C14283T, T14317C và G14559A. Các đa hình cũng xuất hiện với tần số rất thấp trong quần thể. Mỗi đa hình chỉ xuất hiện ở trong 2-3 mấu.

\section{BÀN LUÂ̂N}

4.1. Trình tự và tính đa hình gen ND5

Các nghiên cứu trên thế giới về gen ND5 tập trung chủ yếu vào nghiên cứu các quan hệ di truyền theo mẫu hệ, phân loại các nhóm đơn bội (haplogroups) và các dòng phả hệ hoặc nghiên cứu về các bệnh di truyền liên quan đến ty thể.

Các nghiên cứu về đa hình/đột biến của gen ND5 được sử dụng chủ yếu trong phân loại các nhóm kiểu đơn/nhóm đơn bội hay các dòng phả hệ và các bệnh di truyền có liên quan đến ty thể. 
Silva và đồng tác giả (2003) đã sử dụng các điểm đa hình để phân loại các nhóm đơn bội và nghiên cứu di truyền tiến hoá của những người Mỹ bản sứ di cư từ Châu Á, trong đó đề cập đến điểm đa hình C12705T. Kết quả cho thấy, tỉ lệ tương đồng giữa các đa hình nuleotide cao chứng tỏ các nhóm đơn bội có chung một nguồn gốc và có thể có chung cả lịch sử phát triển[4].

Ngoài nghiên cứu về phân loại các nhóm đơn bội, các tác giả khác lại tập trung nghiên cứu đa hình/đột biến gen ND5 có liên quan đến bệnh tật. Sudoyo và cộng sự (2002) nghiên cứu 19 bệnh nhân mắc bệnh LiHON có nguồn gốc dân tộc Đông Nam Á nhằm xác định mối liên quan giữa các kiểu đơn của DNA ty thể có liên quan đến đột biến này, đã công bố những điểm đột biến C12405T, G12406A C12882T và G13759A [5]. Young và cộng sự (2005) đề cập về các đột biển DNA ty thể có liên quan với bệnh khiếm thính và đã phát hiện thấy điểm A12358G xuất hiện trong một trong 4 phả hệ người Trung Quốc thuộc các nhóm đơn bội Đông Á khác nhau[6]. Divne (2003) nghiên cứu về quan hệ của hệ gen ty thể với triệu chứng đột tử ở trẻ em (SIDS sudden infant death syndrome) ở 20 trẻ em mắc bệnh phát hiện các đột biến thay thế A11467G, A12308G và G12372A đều xuất hiện ở cả 4 trẻ mắc bệnh[7]. Như vậy, tính đa hình/đột biến của gen ND5 ty thể có thể liên quan tới nhiều bệnh tật khác nhau, vì vậy có thể được sử dụng làm chỉ thị di truyền. Các số liệu trình tự chúng tôi thu được cùng với các vị trí đa hình/đột biến đã phát hiện được cung cấp dữ liệu cho những nghiên cứu tiếp theo về bệnh di truyền liên quan đến ty thể ở người Việt Nam.

4.2. Trình tự và tính đa hình gen ND6. Cho đến nay, có hơn 80 điểm đột biến/ đa hình ở gen ND6 ty thể đã công bố trên trang Web http://www.mitomap.org. Trong đó, khoảng 40 điểm đa hình là các thay thế đồng nghĩa, khoảng hơn 20 điểm đột biến/ đa hình gây ra các bệnh truyền ty thể với trên 10 điểm đột biến được xác định là nguyên nhân gây ra LHONं.

Trong các thay thế đồng nghĩa đã công bố, hầu hết không biểu hiện tính trạng đặc biệt hay không gây ra triệu chứng bệnh nào. Tuy nhiên, có một số thay thế đồng nghĩa xuất hiện ớ những bệnh nhân mắc LHON, u tuyến giáp, ung thư gan và MELAS, đó là các điểm thay thế: C14281A， C14284A， G14364A， A14386G, A14388G và $T 14470 C$.

Liệt thân kinh thị giác di truyền Leber là nguyển nhân gây ra bệnh mù di truyền ở người.
Khoảng $90 \%$ bệnh nhân mắc bệnh này mang ít nhất một trong ba đột biến: G3460A trên gen ND1, G11778A trên gen ND4, và T14484C trên gen ND6. Đột biến T14484C khác với 2 đột biến còn lại ở chố nó xuất hiện với tần số cao ở nhóm đơn bội J (khoảng 75\% cá thể mang đột biến này thuộc nhóm đơn bội J).

Ugalde và đồng tác giả (2003) đã tìm thấy đột biến T14487C ở một bệnh nhân mắc hội chứng Leigh. Đây là trường hợp dị tế bào chất ở gen ND6 ty thể, làm thay đổi amino acid ở vị trí 63 từ Methionine thành Valine. Nhóm tác giả này đã nhận thây ở người mẹ của bệnh nhân có $24 \%$ ty thế mang đột biến trong máu còn bệnh nhân có $65 \%$ ty thể mang đột biến ở cớ, gan và $86 \%$ trong nguyên bào sợi. Điều này được giải thích bởi lý do: các đột biến ty thể có thể gây ra bệnh hay không còn phụ thuộc vào tỷ lệ ty thể mang đột biến đó trong cơ thể, cũng như phụ thuộc và̀ cơ quan chứa ty thể mang đột biến[

\section{KẾT LUẬN}

Nghiên cứu đã cung cấp số liệu về tính đa hình trình tự gen mã hóa ND5 và ND6 ở người dân tộc GiaRai và Ede sống ở Tây Nguyên.

\section{TÀI LIẸU THAM KHẢO}

1. Anderson S., Bankier A., Barrell B. et al (1981). Sequence and organization of the human mitochondrial genome. Nature 290: 457 - 465.

2. Shoffner J.M., Wallace D.C. (1995) Oxidative phosphorylation diseases. The Metabolic and Molecular Bases of Inherited Disease. 1: 1535-1609.

3. Andrew R.M., Kubacka I., Chinery P.E. et al (1999). Reanalysis and revision of the Cambridge reference sequence for human mitochondrial DNA. Nat Genet 23 - 147.

4. Silva W.A., Bonatto S.L., Holanda A.J.et al (2002). Mitochondrial genome diversity of Native Americans supports a single early entry of founder populations into America. Am J Hum Genet 71(1):187-92.

5. Sudoyo H, Suryadi H, Lertrit Pet al (2002) Asianspecific mtDNA backgrounds associated with the primary G11778A mutation of Leber's hereditary optic neuropathy. J Hum Genet 47 (11): 594-604

6. Young WY, Zhao L, Qian Yet al (2005) Extremely low penetrance of hearing loss in four Chinese families with the mitochondrial 12S rRNA A1555G mutation. Biochem Biophys Res Commun 328(4):1244-51

7. Divne AM, Rasten-Almqvist $P$, Rajs Jet al (2003) Analysis of the mitochondrial genome in sudden infant death syndrome. Acta Paediatr 92(3):386-8

8. Zhadanov SI, Atamanov VV, Zhadanov NIet al (2005) A novel mtDNA ND6 gene mutation associated with LHON in a Caucasian family. Biochem Biophys Res Commun 332(4): 111511-21. 